\title{
STARK BROADENING OF ISOIAATED LINES FROM MULTIPLY CHARGED IONS
}

\author{
By \\ J. D. Hey \\ Physics Department, Univers ity of Cape Town, \\ Rondebosch 7700, South Africa
}

When calculating the Stark widths of isolated lines of multiply charged ions with several bound electrons, radiated by dense, hot plasmas, the existing theories of Stark broadening $(1,2)$ which have been applied mainly to lower-temperature measurements on singly-ionized species, need to be modified in several respects. These modifications involve taking more careful account of the complexities of the particular atomic structure: e.g. deviations from LS coupling, configuration mixing, and optically forbidden transitons. Earlier work, ${ }^{(3-5)}$ showing explicitly the relationship between the Stark widths and the oscillator strengths for the collision-induced transitions which contribute to the width, is extended. Some of the principles involved will be discussed and,' if time permits, comparison will be made between calculations and the results of several critically selected experiments ${ }^{(6)}$ on spect ral lines in the near UV (2000-3500 \&).

1. H. R. Griem, Phys. Rev.165, 258 (1968).

2. H. R. Griem, Spectral Line Broadening by Plasmas. Academic Press, New York (1974).

3. J.D. Hey, J. Quant. Spectr. Rad. Trans. (In press, 1977).

4. J.D. Hey, J. Quant. Spectr. Rad. Trans. 16, 575 (1976).

5. J.D. Hey and R. J. Bryan. J. Quant. Spectr.Rad. Trans. (In press, 1977).

6. N. Konjevic and W. L. Wiese, J.Phys. Chem. Reference Data 5 , 259 (1976). 